\title{
COMPORTAMENTO INGESTIVO DE NOVILHOS MESTIÇOS TERMINADOS EM CONFINAMENTO ALIMENTADOS COM BORRA DE SOJA
}

\section{INGESTIVE BEHAVIOR OF STEERS FINISHED ON FEEDLOT FED WITH SOYBEAN SOPASTOCK}

\author{
Álisson Marian Callegaro ${ }^{*}$ \\ Dari Celestino Alves Filho ${ }^{1}$ \\ Luiz Ângelo Damian Pizzuti ${ }^{1}$ \\ Luciane Rumpel Segabinazzi ${ }^{2}$ \\ Ivan Luiz Brondani ${ }^{1}$ \\ Ana Paula Machado Martini ${ }^{1}$ \\ 1Universidade Federal de Santa Maria, Santa Maria, RS, Brasil. \\ 2Universidade Federal do Pampa, Dom Pedrito, RS, Brasil. \\ *Autor para correspondência - mcalisson@hotmail.com
}

\section{Resumo}

Este trabalho objetivou avaliar os efeitos da inclusão da borra de soja no comportamento ingestivo de 30 novilhos mestiços Charolês/Nelore, confinados, com 20 meses de idade e peso médio inicial de $328,3 \mathrm{~kg}$. Cada grupo experimental foi composto por seis animais, distribuídos nos tratamentos: 00; 30; 60; 90 e $120 \mathrm{~g}$ de borra de soja por $1000 \mathrm{~g}$ de matéria seca na dieta, os quais continham 29,0; 47,$3 ; 66,7 ; 86,8$ e 106,8 g de extrato etéreo, respectivamente. O aumento no nível de inclusão de borra de soja na dieta não interferiu no tempo de alimentação, ruminação e ócio $(3,11 ; 13,33$ e 7,55 h, respectivamente). As variáveis número de mastigações por bolo, tempo de mastigação por bolo, número de bolos, número de mastigações diárias e tempo de mastigação total (h/dia) (62; 58; 470; 28978 e 10,65, respectivamente) também não sofreram efeito dos tratamentos. O consumo de matéria seca foi similar, em contrapartida, o consumo de fibra detergente neutro ( $\mathrm{kg} / \mathrm{dia})$ e a eficiência $(\mathrm{g}$ FDN/h) da referida fração apresentaram comportamento linear decrescente com aumento da inclusão de borra. A borra de soja pode ser incluída na dieta de novilhos mestiços confinados até o nível de $120 \mathrm{~g}$ por $1000 \mathrm{~g}$ de matéria seca sem que haja efeitos negativos sobre as principais variáveis relativas ao comportamento ingestivo.

Palavras-chave: atividades diárias; casca de soja; consumo de matéria seca; extrato etéreo.

\begin{abstract}
This study aimed to evaluate the effects of soybean sopastock inclusion on the ingestive behavior of 30 crossbred Charolais / Nellore steers on feedlot, at 20 moths of age and with initial average weight of $328.3 \mathrm{~kg}$. Each experimental group was composed by six animals, distributed into treatments: 00; $30 ; 60 ; 90$ and $120 \mathrm{~g}$ of soybean soapstock per $1,000 \mathrm{~g}$ of dry mater in the diet. Each treatment contained $29.0 ; 47.35 ; 66.6 ; 86.8$ and $106.8 \mathrm{~g}$ of ether extract, respectively. The increase of soybean soapstock in diet did not interfere with feeding, rumination, and idle times $(3.11 ; 13.33$ and 7.55 hours, respectively). The variables number of chews per bolus, time of chew per bolus, number of
\end{abstract}


daily chews and total chew time (h/day) $(62 ; 58 ; 470 ; 28,978$ and 10.65 , respectively) also were not affected by the treatments. Dry matter intake was similar among treatments; however, neutral detergent fiber intake (kg/day) and the efficiency of this fraction ( $\mathrm{gDN} / \mathrm{h}$ ) decreased linearly with the inclusion of soybean soapstock to diet. Therefore, the inclusion of soybean soapstock did not change the ingestive behavior of steers, and it can be used in diets of crossbred steers in feedlot up to the level of $120 \mathrm{~g}$ per $1000 \mathrm{~g}$ of dry matter.

Keywords: daily activities; dry matter intake; ether extract; soybean hull.

Recebido em: 03 de fevereiro de 2014.

Aceito em: 15 de março de 2018.

\section{Introdução}

Com intuito de aprimorar os índices produtivos, é importante buscar maneiras de melhor compreender as respostas dos bovinos nos diferentes sistemas de produção. Para o entendimento completo do consumo diário de alimentos, é preciso estudar seus componentes individualmente, os quais devem ser descritos pelo tempo de alimentação e eficiência alimentar. Cada um desses fatores é resultado da interação entre o metabolismo animal e as propriedades físicas e químicas da dieta, estimulando receptores da saciedade ${ }^{(1)}$. Assim, o estudo do comportamento ingestivo é uma importante ferramenta para aprimorar o desempenho animal ${ }^{(2)}$.

O confinamento e suas alternativas alimentares compreendem na atualidade o principal meio de estudo da etologia, não devido apenas à importância e ao crescimento nos últimos anos, mas pela possibilidade de dessecação do comportamento animal. Dessa forma, quando surge uma nova proposta alimentar, é necessário investigar não apenas a resposta do desempenho animal, mas o respectivo efeito no comportamento ingestivo diário.

A inclusão de gorduras nas dietas de bovinos terminados em confinamento vem sendo uma alternativa pesquisada ${ }^{(3,4)}$. O uso de fontes de lipídios na dieta de bovinos, além de favorecer a absorção de vitaminas (A, D, E, e K) e participar de outras importantes funções metabólicas, apresenta a vantagem de aumentar a densidade energética por unidade de massa, por possuir cerca de 2,25 vezes mais energia em relação aos carboidratos. Entretanto, o uso de lipídios em excesso na dieta de ruminantes pode causar problemas na fermentação ruminal, pois além de dificultar a aderência bacteriana à partícula do alimento, pode acarretar problemas que limitam a ingestão de alimentos ${ }^{(5)}$.

Entre as fontes de gordura disponíveis, cita-se a borra de soja que, por ser um resíduo oriundo do processamento da soja, apresenta expressiva disponibilidade comercial conciliada a preço acessível, nas regiões onde as indústrias extraem o óleo vegetal por meio de solvente. Com a expansão da agricultura no território nacional, aumentou a disponibilidade de subprodutos. Nos últimos 14 anos, essa atividade cresceu aproximadamente $59 \%$ em relação à área cultivada e $129 \%$ em relação à produtividade. Dessa produção, $49 \%$ correspondem atualmente ao grão de soja ${ }^{(6,7)}$. Assim sendo, é larga a disponibilidade do subproduto borra de soja.

Além disso, a borra de soja apresenta alta densidade energética (1931,1 g de nutrientes digestíveis totais por quilograma de matéria seca), estado físico pastoso e alta palatabilidade ${ }^{(8,9)}$. $\mathrm{O}$ uso desse subproduto é conhecido na dieta de monogástricos. Todavia, as informações a respeito de desempenho animal são escassas para ruminantes e praticamente inexistentes quanto ao 
comportamento alimentar.

Diante do exposto, objetivou-se avaliar os efeitos dos níveis de inclusão de borra de soja sobre o comportamento ingestivo de novilhos terminados em confinamento.

\section{Material e Métodos}

Foram utilizados 30 machos castrados mestiços Charolês/Nelore com idade e peso vivo inicial de 20 meses e $328,3 \mathrm{~kg}$, respectivamente. Os novilhos foram escolhidos ao acaso do rebanho experimental do Laboratório de Bovinocultura de Corte, contemporâneos e recriados em um mesmo sistema de alimentação até o início da terminação.

Os animais foram distribuídos em número de seis unidades por grupo experimental, submetidos aos seguintes tratamentos: 00; 30; 60; 90 e 120 g de borra de soja por $1000 \mathrm{~g}$ de matéria seca na dieta, que continham 29,$0 ; 47,3 ; 66,7 ; 86,8$ e 106,8 g de extrato etéreo (EE). Os novilhos foram alojados em baias individuais de $12 \mathrm{~m}^{2}$, coberta, com piso de alvenaria, providas de bebedouro e comedouro individualizado. $\mathrm{O}$ período de adaptação dos animais às dietas, às instalações e ao manejo alimentar foi de 16 dias e o período experimental de 84 dias.

Durante o experimento, todos os animais receberam dieta com relação volumoso:concentrado de 40:60 (base na matéria seca), calculada de acordo com as exigências sugeridas pelo NRC ${ }^{(10)}$, objetivando ganho de peso diário de $1,2 \mathrm{~kg} /$ dia, estimando-se o consumo de matéria seca em $2,5 \mathrm{~kg}$ de matéria seca/100 kg de peso vivo, sendo as dietas isonitrogenadas.

O volumoso fornecido aos animais foi silagem de milho e o concentrado composto por casca de soja, farelo de soja, borra de soja, milho, cloreto de sódio e calcário calcítico. A alimentação dos animais foi ad libitum, fornecida em duas refeições diárias $(08 \mathrm{~h} 30 \mathrm{~min}$ e $14 \mathrm{~h})$, sendo as sobras pesadas e ajustadas diariamente de modo que oscilassem entre 50 e $80 \mathrm{~g} / \mathrm{kg}$ de matéria seca do total de alimento ofertado.

À medida que era confeccionada uma nova partida de concentrado, coletavam-se amostras dos ingredientes. As amostras de borra de soja foram armazenadas em freezer a temperatura de $-18{ }^{\circ} \mathrm{C}$, e, posteriormente, encaminhadas para análise laboratorial. Semanalmente, foram coletadas amostras de sobras e de silagem, que foram pré-secadas em estufa de ar forçado a $55^{\circ} \mathrm{C}$ durante 72 duas horas para determinação de matéria parcialmente seca. Após pré-secagem, as amostras foram moídas em moinho tipo Willey, com peneiras de crivo de $1 \mathrm{~mm}$.

Nas amostras dos componentes das dietas (exceto a borra de soja) e sobras, foram determinados os teores de matéria seca (MS), matéria orgânica (MO), matéria mineral (MM), extrato etéreo (EE) e proteína bruta segundo $\mathrm{AOAC}^{(11)}$.

Na Tabela 1, constam a participação dos ingredientes e os teores médios percentuais de matéria seca (MS), matéria orgânica (MM), proteína bruta (PB), extrato etéreo (EE), fibra detergente neutro (FDN) e ácido (FDA), nitrogênio insolúvel em detergente neutro (NIDN) e ácido (NIDA), lignina detergente ácido (LDA) e nutrientes digestíveis totais (NDT) das dietas, conforme Weiss et al. ${ }^{(12)}$ (NDT = carboidratos não fibrosos digestivos + proteína bruta digestiva $+($ extrato etéreo digestivo x 2,25) + fibra detergente neutro - 7). 
A coleta de dados do comportamento ocorreu durante o período experimental (84 dias), distribuídos em quatro períodos, de dois dias cada. As observações do comportamento ingestivo consistiram nos registros das informações dos tempos diários despendidos com alimentação, ruminação e ócio, em pé ou deitado, tomadas a cada cinco minutos. Os avaliadores foram previamente treinados ao inicio do comportamento animal, em que dois avaliadores permaneceram durante oito horas consecutivas observando 15 animais, posteriormente foi efetuada a troca de avaliadores e, assim, sucessivamente até atingir 48 horas. As instalações foram mantidas com iluminação artificial durante a noite.

O número de mastigações merícicas por bolo ruminal (NMMB) e o tempo despendido na mastigação merícica por bolo ruminal (TMMB) foram obtidos através de observações de cada animal em cada período de avaliação. Para registro do TMMB, utilizou-se um cronômetro digital. Os dados do comportamento ingestivo foram interpretados conforme Bürger et al. ${ }^{(13)}$, onde: ERMS=CMS/TRT; ERFDN=CFDN/TRT; $\quad$ TMT=TA+TRT; $\quad$ NBOLO=TRT/TMMB; NMMD=NMMB*NBOLO; TOT=TOE+TOD e TRT=TRE+TRD; em que: ERMS = eficiência de ruminação de $\mathrm{MS}, \mathrm{g} \mathrm{MS} / \mathrm{h}$; CMS = consumo de MS, g MS/dia; ERFDN = eficiência de ruminação da FDN, g FDN/h; CFDN = consumo de FDN, g FDN/dia; TMT = tempo de mastigação total, h/dia; TA = tempo de alimentação total, $\mathrm{h} / \mathrm{dia}$; tempo de ruminação total, $\mathrm{h} / \mathrm{dia} ; \mathrm{NBOLO}=$ número de bolos mastigados por dia, $\mathrm{n}^{\circ} / \mathrm{dia}$; $\mathrm{TMMB}=$ tempo de mastigação merícica por bolo ruminal, seg/bolo; NMMD = número de mastigadas merícicas por dia, $\mathrm{n}$ /dia; TOT = tempo de ócio total, h/dia; TOE = tempo de ócio em pé, h/dia; TOD = tempo de ócio deitado, $\mathrm{h} /$ dia; TRT $=$ tempo de ruminação total, $\mathrm{h} /$ dia; $\mathrm{TRE}=$ tempo de ruminação em pé, $\mathrm{h} /$ dia; TRD = tempo de ruminação deitado.

Tabela 1. Participação dos ingredientes (base na matéria seca) e composição bromatológica das dietas experimentais

\begin{tabular}{lccccc}
\hline \multirow{2}{*}{ Ingredientes, $\mathbf{g} / \mathbf{k g}$ de matéria seca } & \multicolumn{5}{c}{ Níveis de inclusão de borra de soja (g/kg MS) } \\
\cline { 2 - 6 } & $\mathbf{0 0}$ & $\mathbf{3 0}$ & $\mathbf{6 0}$ & $\mathbf{9 0}$ & $\mathbf{1 2 0}$ \\
\hline Silagem de milho & 384,5 & 387,7 & 390,9 & 394,2 & 398,0 \\
Casca de soja & 486,3 & 445,2 & 405,0 & 355,0 & 301,0 \\
Farelo de soja & 113,9 & 122,5 & 129,1 & 139,3 & 144,5 \\
Borra de soja & - & 29,4 & 59,7 & 89,7 & 118,3 \\
Milho & - & - & - & 0,61 & 2,26 \\
Calcário calcítico & 6,2 & 6,1 & 6,1 & 6,7 & 6,6 \\
Cloreto de sódio & 9,2 & 9,2 & 9,1 & 9,1 & 9,0 \\
\hline & Composição bromatológica & & & \\
\hline Matéria seca * & 665,7 & 656,5 & 647,2 & 637,9 & 628,6 \\
Proteína bruta & 134,1 & 136,7 & 138,5 & 141,7 & 142,7 \\
Extrato etéreo & 29,0 & 47,3 & 66,7 & 86,8 & 106,8 \\
Matéria mineral & 58,7 & 58,6 & 58,4 & 58,3 & 57,3 \\
Fibra detergente neutro & 564,6 & 545,5 & 526,4 & 501,4 & 473,9 \\
Fibra detergente ácido & 377,4 & 362,3 & 347,2 & 327,0 & 304,0 \\
Lignina & 33,0 & 32,8 & 32,6 & 32,3 & 31,9 \\
Nutrientes digestíveis totais & 638,4 & 668,5 & 696,5 & 728,2 & 761,8 \\
Energia digestivel, Mcal/Kg & 2,80 & 2,93 & 3,06 & 3,20 & 3,35 \\
\hline
\end{tabular}

* $\mathrm{g} / \mathrm{kg}$ de matéria natural.

O delineamento utilizado foi o inteiramente casualizado, com cinco tratamentos e seis repetições, sendo o animal a unidade experimental. Os dados analisados de cada unidade experimental correspondem às médias das avaliações de cada animal do período experimental. As variáveis foram testadas quanto à normalidade pelo teste de Shapiro-Wilk. Os dados foram submetidos à análise de variância e teste $\mathrm{F}$, pelo procedimento PROC GLM do $\mathrm{SAS}^{(14)}$ e as médias comparadas pelo teste " $\mathrm{t}$ " 
considerando $5 \%$ de significância, bem como foi realizado teste de correlação de Pearson pelo procedimento PROC CORR. Já para o estudo da regressão polinomial, pelo comando PROC RSREG. $\mathrm{O}$ grau do polinômio adotado para cada variável foi dado pelo critério de significância pelo teste $\mathrm{F}$ e pelo coeficiente de determinação quando houve significância para cada grau de polinômio.

Foram feitas análises de falta de ajuste (lack-of-fit) dos modelos de regressão escolhidos e análise de resíduos para detecção da existência de outliers, não sendo detectadas observações que fossem consideradas anormais nesta última análise. Os dados foram analisados com auxilio do pacote estatístico SAS ${ }^{(14)}$.

\section{Resultados e Discussão}

A inclusão de borra de soja na dieta de bovinos não influenciou $(\mathrm{P}>0,05)$ as atividades do comportamento ingestivo dos animais (Tabela 2), sendo que os animais passaram em média 3,11; 7,55 e 13,33 horas envolvidos, respectivamente, com alimentação, ruminação e ócio.

A ausência de diferença na distribuição das atividades do comportamento ingestivo ao longo do dia pode estar associada à relação volumoso: concentrado ter sido semelhante entre as dietas (Tabela 1), pois o tempo despendido com a ruminação é influenciado pela natureza da dieta, e proporcional ao teor da parede celular dos volumosos (hemicelulose e celulose), onde quanto maior a participação de volumoso na dieta, maior o tempo gasto em ruminação ${ }^{(15)}$. Fatores inerentes ao tempo destinado a ruminação estão diretamente relacionado à qualidade e quantidade de alimento consumido. $\mathrm{O}$ fornecimento de cereais inteiros em vez de triturados pode aumentar o tempo de destinado a mastigação durante o consumo e ruminação ${ }^{(16)}$. Além disso, Barros et al. ${ }^{(17)}$ descrevem que alimentos mais degradáveis têm maior taxa de passagem, logo necessitam menor tempo para ruminação.

O tempo de ruminação foi inversamente correlacionado com o teor de FDN da dieta, sendo valor obtido de média magnitude $(\mathrm{r}=-0,42 ; \mathrm{P}<0,0202)$. Resultados discordantes da literatura, pois pesquisas $^{(3,18)}$ demonstram que em geral ocorre aumento do tempo de ruminação conforme eleva-se o teor de FDN. Dessa forma, esperava-se que quanto maior fosse o teor de FDN na dieta maior seria o tempo despendido com ruminação. Pereira et al. ${ }^{(19)}$ observaram que novilhas leiteiras alimentadas com dietas contendo $60 \%$ de FDN despenderam 28,0; 15,8 e 20,2\% a mais de tempo envolvidas com a atividade de mastigação, ruminação e ruminação total, respectivamente, quando comparadas com aquelas alimentadas com rações contendo $30 \%$ de FDN. Provavelmente o resultado da presente pesquisa está relacionado à falta de fibra fisicamente efetiva proporcionada pelo ingrediente casca do grão de soja (fornecida na forma que foi obtida na industria de processamento da soja), embora apresente alto teor de FDN, apresenta apenas 3\% de fibra fisicamente efetiva, sendo inferior ao grão de milho moído que apresenta $3,2 \%{ }^{(16)}$.

Além disso, os animais no presente estudo permaneceram em média 6,89 e 8,93 horas ruminando deitado e em ócio deitado, respectivamente (Tabela 2), contribuindo para que os novilhos não apresentassem gasto de energia com essa posição, deslocando-se menos dentro das baias e consequentemente metabolizassem essa energia para desenvolvimento muscular e deposição de gordura na carcaça. Segundo Hinton ${ }^{(20)}$, a energia gasta com a caminhada de bovinos é de 0,62 $\mathrm{kcal} / \mathrm{km}$ de deslocamento horizontal e de $6,69 \mathrm{kcal} / \mathrm{km}$ de deslocamento vertical. 
Tabela 2. Médias, coeficientes de variação e probabilidades das atividades do comportamento ingestivo de novilhos submetidos a niveis de inclusão de borra de soja na dieta

\begin{tabular}{|c|c|c|c|c|c|c|c|}
\hline \multirow{3}{*}{ Variáveis } & \multirow{2}{*}{\multicolumn{5}{|c|}{$\begin{array}{c}\text { Níveis de inclusão de borra de soja (g/kg } \\
\text { MS) }\end{array}$}} & \multirow{3}{*}{$\mathrm{CV}$} & \multirow{3}{*}{$\mathbf{P}>\mathbf{F}$} \\
\hline & & & & & & & \\
\hline & 00 & 30 & 60 & 90 & 120 & & \\
\hline Alimentação, horas/dia & 3,45 & 3,17 & 3,05 & 2,90 & 2,97 & 12,7 & 0,1776 \\
\hline Ócio Deitado, horas/dia & 9,32 & 9,61 & 8,65 & 8,46 & 8,63 & 11,4 & 0,2641 \\
\hline Ócio em Pé, horas/dia & 3,93 & 4,04 & 4,83 & 4,84 & 4,36 & 23,0 & 0,3927 \\
\hline Ócio Total, horas/dia & 13,25 & 13,64 & 13,48 & 13,30 & 12,99 & 4,5 & 0,4425 \\
\hline Ruminação Deitado, horas/dia & 6,81 & 6,55 & 6,76 & 7,19 & 7,16 & 9,9 & 0,4522 \\
\hline Ruminação em Pé, horas/dia & 0,50 & 0,63 & 0,71 & 0,61 & 0,85 & 59,7 & 0,6177 \\
\hline Ruminação Total, horas/dia & 7,31 & 7,18 & 7,47 & 7,80 & 8,01 & 7,9 & 0,1351 \\
\hline \multicolumn{8}{|c|}{ Atividade relacionadas à ruminação } \\
\hline $\mathrm{N}^{\circ}$ de mastigadas, $\mathrm{n}^{\circ} /$ bolo ruminal & 59 & 60 & 61 & 67 & 63 & 13,02 & 0,4717 \\
\hline $\begin{array}{l}\text { Tempo de mastig. por bolo ruminal, } \\
\text { seg }\end{array}$ & 55 & 57 & 57 & 63 & 59 & 12,44 & 0,4272 \\
\hline $\mathrm{N}^{\circ}$ de bolos mastigados, $\mathrm{n}^{\circ} / \mathrm{dia}$ & 492 & 451 & 472 & 446 & 492 & 17,06 & 0,7741 \\
\hline $\mathrm{N}^{\circ}$ de mastigadas, $\mathrm{n} \%$ dia & 28431 & 27079 & 28507 & 29961 & 30912 & 10,29 & 0,2504 \\
\hline Tempo de mastigação total, $\mathrm{h} / \mathrm{dia}$ & 10,75 & 10,35 & 10,51 & 10,69 & 10,99 & 5,68 & 0,4532 \\
\hline
\end{tabular}

O tempo de ruminação total observado no presente trabalho (Tabela 2) está próximo ao reportado na literatura ${ }^{(4)}$ para bovinos confinados. Souza et al. ${ }^{(21)}$ comentam que maior parte dessa atividade ocorre durante a noite, ao mesmo tempo que é influenciada pelo alimento.

Os tempos destinados ao ócio não diferiram $(\mathrm{P}>0,05)$ com a inclusão de borra de soja na dieta. O ócio é considerado o tempo que o animal fica sem se alimentar ou ruminar, podendo estar deitado, ou em pé, sendo que geralmente os bovinos permanecem em ócio deitado, principalmente à noite. As pesquisas indicam que essa atividade consome cerca de 13,17 e 13,48 hs diárias ${ }^{(2,22)}$, respectivamente, sendo semelhante ao valor do presente estudo, em que os animais permaneceram em ócio, em média 13,3 hs. Conforme alguns autores ${ }^{(23)}$ o maior tempo de ócio pode ser explicado em função do menor tempo de alimentação dos animais (Tabela 2) o qual não comprometeu o consumo de matéria seca (Tabela 3; P>0,05). Corroborando com Deswysen et al. ${ }^{(23)}$ que relatam que os tempos de descanso entre as refeições, sua duração e seu padrão de distribuição são influenciados pelas atividades de ingestão de alimento.

O consumo de matéria seca diário, em percentagem do peso vivo e em unidade de tamanho metabólico não foram influenciados $(\mathrm{P}>0,05)$ pela inclusão da borra de soja (Tabela 3). Provavelmente esse resultado esta relacionado à limitação no consumo de matéria seca pela densidade energética da dieta (NDT) à medida que aumentou a inclusão de borra de soja. Pois embora não tenha ocorrido diferença no consumo de matéria seca $(\mathrm{P}>0,05)$, os novilhos diminuíram $8,50 \%$ o consumo de matéria seca (\% peso vivo), do nível menos energético $(63,8 \%$ de NDT) para o mais energético $(76,18 \%$ de NDT).

Os valores de consumo de matéria seca encontrados no presente estudo são semelhantes aos descritos por Freitas et al. ${ }^{(3)}$, nos quais avaliaram a substituição da silagem de milho pela de girassol na terminação de novilhos cruzas Charolês x Nelore, e constataram que o consumo diário de matéria seca variou de 8,19 a 9,07 kg/dia, em percentagem do peso vivo, oscilando entre 2,36 a 2,56 kg/100 $\mathrm{kg}$ de peso vivo. 
A inclusão de borra de soja na dieta proporcionou decréscimo linear no consumo de fibra em detergente neutro, expresso nas diferentes formas (Tabela 3; $\mathrm{P}<0,05$ ). O teor de fibra detergente neutro na ração diminuiu (Tabela 1) com aumento do nível de inclusão de borra de soja na dieta, consequentemente o consumo da referida fração, comportamento que já era esperado, pois o teor de fibra detergente neutro da borra é ausente (Tabela 1).

Tabela 3. Médias, coeficientes de variação e probabilidades para o consumo diário de matéria seca e de fibra em detergente neutro, eficiências de ruminação da matéria seca e de fibra em detergente neutro de novilhos submetidos a níveis de inclusão de borra de soja

\begin{tabular}{|c|c|c|c|c|c|c|c|}
\hline \multirow[t]{2}{*}{ Variáveis } & \multicolumn{5}{|c|}{$\begin{array}{c}\text { Níveis de inclusão de borra de soja } \\
(\mathrm{g} / \mathrm{kg} \mathrm{MS})\end{array}$} & \multirow[t]{2}{*}{$\mathrm{CV}$} & \multirow[t]{2}{*}{$\mathbf{P}>\mathbf{F}$} \\
\hline & 00 & 30 & 60 & 90 & 120 & & \\
\hline Consumo de matéria seca, $\mathrm{kg} / \mathrm{dia}$ & 10,83 & 10,31 & 10,23 & 10,52 & 9,64 & 13,34 & 0,6620 \\
\hline $\begin{array}{l}\text { Cons. mat. seca \% peso vivo, } \\
\mathrm{kg} / 100 \mathrm{~kg} \mathrm{PV}\end{array}$ & 2,71 & 2,61 & 2,54 & 2,64 & 2,48 & 6,24 & 0,1592 \\
\hline $\begin{array}{l}\text { Cons. mat. seca tamanho } \\
\text { metabólico, } \mathrm{g} / \mathrm{PV}^{0,75}\end{array}$ & 121,21 & 116,14 & 113,74 & 117,90 & 109,93 & 6,17 & 0,1153 \\
\hline $\begin{array}{l}\text { Consumo de fibra detergente } \\
\text { neutro, } \mathrm{kg} / \mathrm{dia}^{1}\end{array}$ & 6,08 & 5,58 & 5,36 & 5,24 & 4,53 & 13,31 & 0,0009 \\
\hline $\begin{array}{l}\text { Cons. fibra deterg. neutro } \% \text { peso } \\
\text { vivo, } \mathrm{kg} / 100 \mathrm{~kg} \mathrm{PV}^{2}\end{array}$ & 1,52 & 1,41 & 1,33 & 1,31 & 1,16 & 6,83 & 0,0001 \\
\hline $\begin{array}{l}\text { Cons. fibra deterg. neutro } \\
\text { tamanho metabólico, } \mathrm{g} / \mathrm{PV}^{0,753}\end{array}$ & 67,90 & 62,77 & 59,46 & 58,63 & 51,52 & 6,82 & 0,0001 \\
\hline $\begin{array}{l}\text { Eficiência de ruminação da mat. } \\
\text { seca, g MS/h }\end{array}$ & 1518 & 1462 & 1388 & 1354 & 1221 & 16,05 & 0,2241 \\
\hline $\begin{array}{l}\text { Eficiência de ruminação da fibra } \\
\text { deterg. neutro, g FDN } / h^{4}\end{array}$ & 853 & 791 & 728 & 674 & 573 & 15,22 & 0,0001 \\
\hline
\end{tabular}

O consumo de matéria seca foi significativamente correlacionado com o consumo de fibra detergente neutro ( $\mathrm{r}=0,9241 ; \mathrm{P}<0,0001)$, demonstrando que os animais que consumiram maior quantidade de matéria seca ingeriram maior quantidade de fibra detergente neutro. Nesse caso o teor de FDN não foi limitante no consumo de matéria seca, provavelmente em função da alta digestibilidade da borra soja, que possui $193 \%$ de nutrientes digestíveis totais.

Em relação à eficiência de ruminação de matéria seca em g de $\mathrm{MS} / \mathrm{h}$, esta não diferiu $(\mathrm{P}>0,05)$ entre os tratamentos estudados. Esse resultado pode ser explicado pelo fato de não ter ocorrido diferença significativa no consumo de matéria seca (Tabela 3) e no tempo total despendido com ruminação (Tabela 2). Na presente pesquisa a eficiência de ruminação da matéria seca foi correlacionada com o consumo de matéria seca $(\mathrm{r}=0,8386 ; \mathrm{P}<0,0001)$ e inversamente correlacionada com o tempo de ruminação $(\mathrm{r}=-0,5732 ; \mathrm{P}<0,0009)$. De acordo com a literatura, elevando-se o nível de inclusão de concentrado na dieta aumenta-se a eficiência de ruminação ${ }^{(14)}$. O resultado para a eficiência de ruminação da matéria seca está associado ao maior peso específico do alimento consumido ${ }^{(15)}$ e da magnitude da variação do teor dos componentes fibrosos da dieta ${ }^{(22)}$. Uma vez que o bolo alimentar regurgitado pelo animal, em dietas com maiores proporções de concentrado, normalmente possui maior densidade (maior teor de matéria seca) e menor quantidade de fibra em detergente neutro, permitindo ao animal realizar menor número de mastigações por bolo e consequentemente, ruminar 
menor número de bolos por dia.

Essas informações são ratificadas por Missio et al. ${ }^{(18)}$, ao estudarem diferentes relações de volumoso: concentrado na dieta de novilhos, com aumento no nível de concentrado observaram semelhança no consumo de matéria seca, porém redução no tempo de alimentação e ruminação, dessa forma melhorando a eficiência de ruminação da matéria seca.

O aumento no nível de borra de soja na dieta acarretou em diminuição na eficiência de ruminação da fibra em detergente neutro ( $\mathrm{P}<0,05$; Tabela 3 ). Pode-se estimar por meio da equação de regressão que o aumento de uma grama na quantidade de borra de soja na dieta, espera-se em média um decréscimo de 22,75 g na eficiência de ruminação da fibra detergente neutro. Isto provavelmente ocorreu em virtude da diferença na degradação ruminal da fibra detergente neutro da dieta, em função do aumento no nível de inclusão de borra de soja, assim diminui a percentagem de fibra detergente neutro e por consequência aumentou a digestibilidade (Tabela 1). Resultados que não eram esperados, pois as eficiências de ruminação e ingestão, expressas em g por hora, podem ser aumentadas para dietas com menor teor de fibra, em razão da maior facilidade em diminuir o tamanho das partículas originadas de materiais fibrosos. Parte desse comportamento é explicada pela participação da fração volumosa mencionada anteriormente, pois esta é a principal determinante do tempo de ruminação.

Freitas et al. ${ }^{(3)}$ verificaram que a eficiência de ruminação da fibra detergente neutro foi maior para a dieta à base de silagem de milho (715,4 g FDN/h) em relação à dieta com $660 \mathrm{~g}$ de silagem de girassol por $\mathrm{kg}$ de matéria seca na fração volumoso $(617,5 \mathrm{~g}$ FDN/h), provavelmente em virtude da diferença na degradação ruminal dessa fibra entre as fontes de volumoso.

Os tempos de ingestão de alimento e de ruminação variam de acordo com o conteúdo de fibra na $\operatorname{dieta}^{(3)}$, dessa forma quando os tempos de ruminação e mastigação são limitados, ocorre redução da produção de saliva, ocasionando diminuição do $\mathrm{pH}$ ruminal $^{(3)} \mathrm{e}$ da digestibilidade da fibra. Entretanto esta situação não ocorreu no presente estudo, onde o tempo de ruminação e de mastigação (Tabela 2) não diferiram $(\mathrm{P}>0,05)$ com a inclusão de borra de soja na dieta, provavelmente em função da mesma relação volumoso: concentrado, impedindo que ocorresse diminuição na produção de saliva e redução no $\mathrm{pH}$ ruminal, e na digestibilidade da fibra. A casca de soja apresenta alto teor de fibra detergente neutro digestível que lhe confere características tamponantes, impedindo variações bruscas do $\mathrm{pH}$, permitindo o crescimento adequado dos microorganismos do rúmen ${ }^{(24)}$. É importante ressaltar que além de atender as exigências nutricionais, é necessário manter o teor de fibra adequado para que se tenha um ambiente ruminal saudável ${ }^{(25)}$.

Os resultados obtidos para número de mastigações merícicas por bolo, tempo de mastigação merícicas por bolo ruminal e número de bolos mastigados por dia não foram influenciados $(\mathrm{P}>0,05)$ pela inclusão de borra de soja na dieta, em média 62 vezes, 58 segundos e 470,6 bolos, respectivamente (Tabela 2). Provavelmente esse resultado esta relacionado ao semelhante consumo de matéria seca, uma vez que, que essas variáveis não estiveram relacionadas $(\mathrm{P}>0,05)$ com o teor de fibra detergente neutro da dieta bem como com o consumo da referida fração. Uma das explicações para o presente fato é a alta digestibilidade do ingrediente casca de soja (pectina), que acabou compensando as atividades mastigatórias dos tratamentos menos energéticos, que apresentam maior teor de fibra detergente neutro. Esse comportamento é decorrente do pequeno tamanho de partícula apresentado pelo ingrediente casca do grão de soja, a qual não possui fibra fisicamente efetiva ${ }^{(16)}$. Conforme Pazdiora et al. ${ }^{(26)}$, a atividade de mastigação durante a ingestão e/ou ruminação atua diretamente na redução das partículas do alimento e implica, indiretamente, nas condições adequadas para celulobiose ruminal, devido ao efeito sobre a produção de saliva. 
Os valores obtidos no presente estudo estão próximos aos descritos por Freitas et al. ${ }^{(3)}$, sendo que os bovinos mastigaram em média 61 vezes, logo levaram em média 56 segundos para mastigar cada bolo ruminal. Polli et al. ${ }^{(27)}$, estudando o comportamento ingestivo de bovinos e bubalinos alimentados com cana-de-açúcar ou silagem de milho, não observaram diferenças quanto ao número de bolos mastigados por dia, sendo que os animais que receberam cana-de-açúcar e silagem de milho ruminaram em média 521 e 575 bolos/dia, respectivamente.

O número de mastigações merícicas por dia é obtido mediante a multiplicação entre o número de mastigações merícicas por bolo $(\mathrm{P}>0,05)$ e o número de bolos ruminais regurgitado durante o dia ( $\mathrm{P}>0,05)$, deste modo não diferiu entre os tratamentos ( $\mathrm{P}>0,05$; Tabela 2$)$, com valores médios de 28.978 mastigadas por dia. Esse valor é intermediário aos observados por Polli et al. ${ }^{(27)}, 28.710$ e 30.988 mastigações por dia para dietas com cana-de-açúcar e silagem de milho respectivamente. Enquanto os autores Freitas et al. ${ }^{(3)}$ encontraram valor superior (34.256) para o tratamento com silagem de milho, comparando ao valor (27.079 mastigadas por dia) do presente estudo, confrontado ao mesmo nível de extrato etéreo (40 g de EE/kg de MS).

A inserção de borra de soja na dieta não alterou o tempo de mastigação diário $(\mathrm{P}>0,05)$, cujo valor médio foi de 10,65 h/dia, inferior ao valor médio descrito por Freitas et al. ${ }^{(3)}$, cujo valor foi de 13,6 $\mathrm{h} /$ dia. Enquanto Bürger et al. ${ }^{(13)}$ trabalhando com bezerros holandeses alimentados com $600 \mathrm{~g}$ de concentrado por kg de matéria seca na dieta, o tempo foi 10,12 $\mathrm{h} /$ dia.

Pelo resultado de análise de variância constatou-se interação entre tratamento x hora $(\mathrm{P}=0,0233)$, sendo que em alguns momentos alternava-se a presença dos animais ao comedouro (Figura 1). Observou-se maior presença dos novilhos no momento em que foi disponibilizada a alimentação ( $8 \mathrm{~h} 30 \mathrm{~min}$ e às $14 \mathrm{~h}$ ) e no final da tarde, entre $16 \mathrm{e} 18 \mathrm{~h}$, não ocorrendo diferença entre os tratamentos estudados $(\mathrm{P}>0,05)$. Os horários de pico de alimentação das $8 \mathrm{~h} 30 \mathrm{~min}$ e das $14 \mathrm{~h}$ coincidem com os horários de fornecimento do alimento, já o horário compreendido entre 16 e $18 \mathrm{~h}$ provavelmente ocorreu devido à temperatura ambiente mais amena, o que estimula a alimentação.

Esses resultados concordam com os observados por Freitas et al. ${ }^{(3)}$ que relatam que a busca de alimento por bovinos confinados ocorre em dois períodos principais (início da manhã e final de tarde) e que o número e a duração das refeições são mais variáveis que os períodos de ruminação. Por outro lado, as atividades ingestivas são ritmadas pela distribuição da dieta e a quantidade ofertada influência os picos de ocorrência da atividade ingestiva ${ }^{(28)}$.

Marques et al. ${ }^{(29)}$ descrevem que em confinamento, a distribuição da alimentação em horário prédeterminado, faz com que a atividade de ingestão seja maior durante o dia. Além disso, segundo Fraser e Broom ${ }^{(30)}$ outro fator que determina quando e o que o animal vai comer é a facilidade com que ele consegue obter os alimentos. 


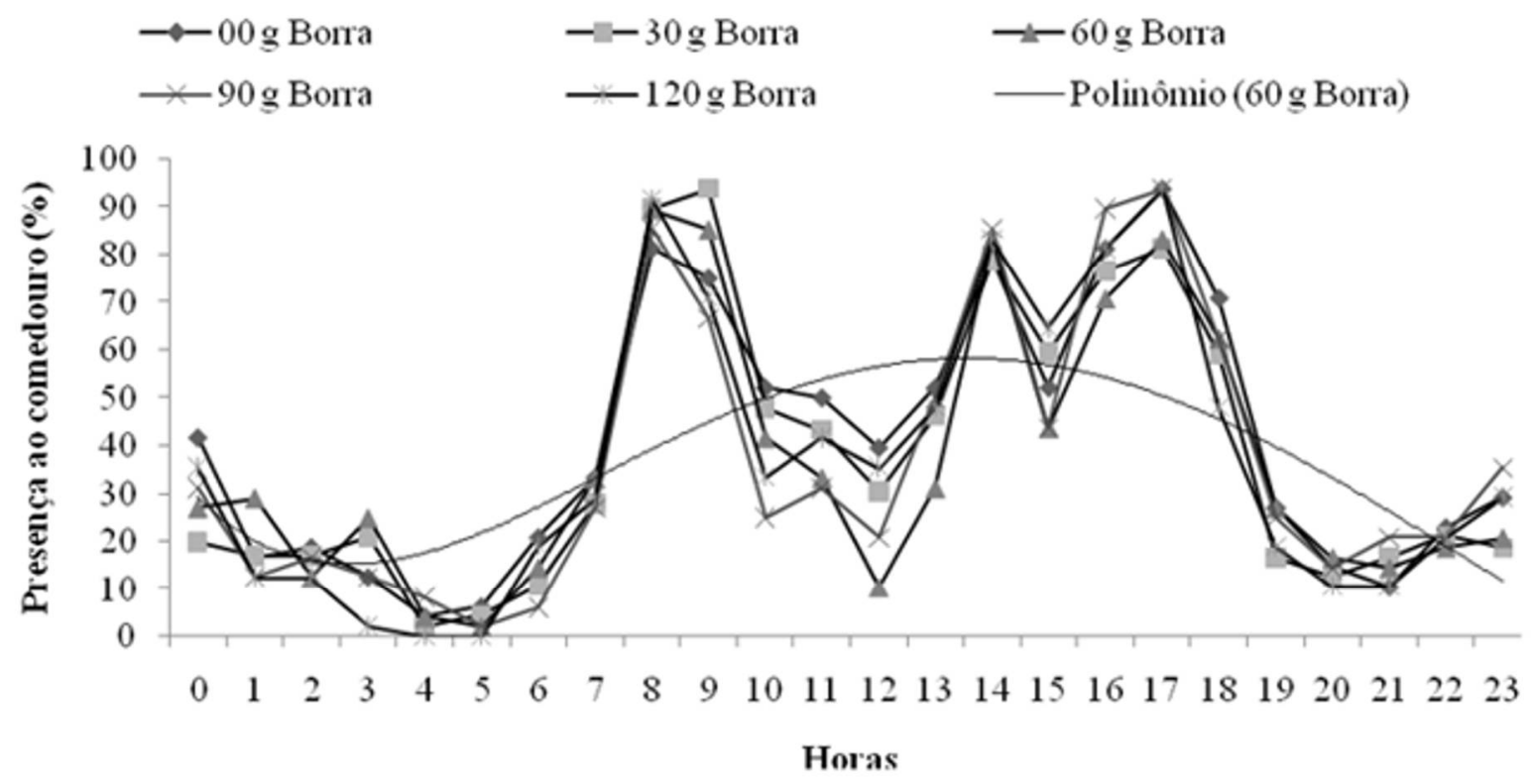

Figura 1. Presença dos animais ao comedouro (\%).

\section{Conclusão}

A inclusão de borra de soja na dieta não interfere no comportamento ingestivo de novilhos mestiços Charolês / Nelore terminados em confinamento alimentados com borra de soja na dieta.

\section{Agradecimentos}

A empresa Bunge ${ }^{\circledR}$ pela doação dos ingredientes para confecção do concentrado.

\section{Referências}

1. Miranda LF, Queiroz, AC de, Valadares Filho SB, et al. Comportamento ingestivo de novilhas leiteiras alimentadas com dietas à base de cana de açúcar. Revista Brasileira de Zootecnia [Internet]. 1999 [Acesso Jan 2014]; 28(3):614-620. Disponível em: <http://www.scielo.br/pdf/rbz/v28n3/a26v28n3.pdf > Portuguese.

2. Cattelam J, Brondani IL, Alves Filho DC, et al. Padrões comportamentais de novilhos confinados com diferentes espaços individuais. Current Agricultural Science and Technology [Internet]. 2013 [Acesso Jul 2014]; 19:82-95. Disponível em: <http://periodicos.ufpel.edu.br/ojs2/index.php/CAST/article/view/3247>. Portuguese.

3. Freitas L da S, Silva JHS da, Segabinazzi LR et al. Substituição da silagem de milho por silagem de girassol na dieta de novilhos confinados: comportamento ingestivo. Revista Brasileira de Zootecnia [Internet]. 2010 [Acesso Jan 2014]; 39(1):225-232. Disponível em: $<$ http://www.scielo.br/pdf/rbz/v39n1/30.pdf $>$. Portuguese.

4. Metz PAMM, Restle, J. Alves Filho, DC et al. Performance of feedlot steers finished with different fat sources in diet. Archivos de Zootecnia [Internet]. 2014 [Acesso Mar 2018]; 63(242):305-313. Disponível em: $<$ http://scielo.isciii.es/pdf/azoo/v63n242/art09.pdf $>$. English. 
5. Kozloski GV. Bioquímica dos ruminantes. $2^{\circ}$ edição revista e ampliada. Santa Maria: Ed. da UFSM, 2009. 216p. Portuguese.

6. CONAB. Companhia Nacional de Abastecimento. Acompanhamento da Safra Brasileira - Grãos. Sexto Levantamento 2017/2018 - Março/2018 [Internet]. 2018 [Acesso Mar 2018]; 5(6):001-129. Disponível em:

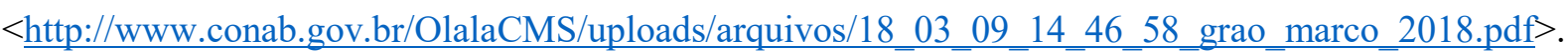

Portuguese.

7. CONAB. Companhia Nacional de Abastecimento. $3^{\circ}$ Levantamento de avaliação de safra 2004/2005 Fevereiro/2005 [Internet]. 2005 [Acesso Mar 2018]; 1(8):01-30, 2005. Disponível em: $<$ http://www.conab.gov.br/OlalaCMS/uploads/arquivos/118f06cc2b4bc79628d8df4f13e82470..pdf $>$.

Portuguese.

8. Shain DH, et al. Effect of a soybean hull: soy lecithin:soapstock mixture on ruminal digestion and performance of growing beef calves and lactating dairy cattle. Journal Animal Science [Internet]. 1993 [Acesso Jan 2014]; 71:1266-1275. Disponível em: <http://www.journalofanimalscience.org/content/71/5/1266.long>. English.

9. Abel-Canies SF, et al. Effect of soybean hulls, soy lecithin, and soapstock mixtures on ruminal fermentation and milk composition in Dairy Cows. Journal Dairy Science [Internet]. 1998 [Acesso Jan 2014]; 81:462-470. Disponível em: < http://www.sciencedirect.com/science/article/pii/S0022030298755985>. English.

10. National Research Council Nutrients requirements of beef cattle. ed. Washington, DC. : National Academy of Sciences, 2000, 242p. English.

11. Association of Official Analytical Chemists. Official Methods of Analysis, $16^{\text {th }}$, 3. ed. AOAC International, Gaithersburg, MD. 1997. English.

12. Weiss WP, Conrad HR, Pierre ST. A theoreticall y based model for predicting total digestible nutrient values of forages and concentrates. Animal Feed Science and Technology, Amsterdam, 39(1-2):95-110, 1992. English.

13. Bürger PJ, Pereira JC, Queiroz AC, et al. Comportamento ingestivo em bezerros holandeses alimentados com dietas contendo diferentes níveis de concentrado. Revista Brasileira de Zootecnia [Internet]. 2000 [Acesso Jan 2014]; 29(1):236-242. Disponível em: <http://www.scielo.br/pdf/rbz/v29n1/5754.pdf. $>$ Portuguese.

14. SAS, Institute Incorporation. SAS Language Reference. Version 6. Cary, NC: SAS institute, 1042, 2001p. English.

15. Van Soest PJ. Nutritional ecology of the ruminant. $2^{\text {nd }}$ ed. Ithaca, New York: Cornell University Prin, 1994. 476p. English.

16. Berchielli TT, Pires AV, Oliveira SG de. Nutrição de Ruminantes. $2^{\circ}$ Ed. Jaboticabal: Funep, 2011, 616 p. Portuguese.

17. Barros RC de, Rocha Júnior VR, Saraiva EP, et al. Comportamento ingestivo de bovinos Nelore confinados com diferentes níveis de substituição de silagem de sorgo por cana-de-açúcar ou bagaço de cana amonizado com uréia. Revista Brasileira de Ciência Veterinária, [Internet]. 2011 [Acesso Jul 2014]; 18(1):6-13. Disponível em: $<$ http://www.rbcv.uff.br/rbcv/article/view/239> Portuguese.

18. Missio RL, Brondani IL, Alves Filho DC, et al. Comportamento ingestivo de tourinhos terminados em confinamento, alimentados com diferentes níveis de concentrado na dieta. Revista Brasileira Zootecnia, [Internet]. 2010 [Acesso Jul 2014]; 39(7):1571-1578. Disponível em: http://www.scielo.br/pdf/rbz/v39n7/a25v39n7.pdf. Portuguese.

19. Pereira JC, Cunha DNFV, Cecon PR, et al. Comportamento ingestivo e taxa de passagem de partículas em novilhas leiteiras de diferentes grupos genéticos submetidas a dietas com diferentes níveis de fibra. Revista Brasileira de Zootecnia [Internet]. 2007 [Acesso Jan 2014]; v.36, supl., p.2134-2142. Disponível em:

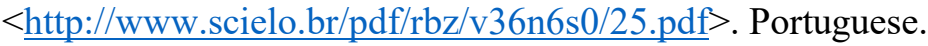


20. Hinton DG. Suplementary feeding of sheep an beef cattle. Melbourne; CSIRO Publishing, 102 p., 2007. English.

21. Souza SRMBO, Ítavo LCV, Rímole J, et al. Comportamento ingestivo diurno de bovinos em confinamento e pastagens. Archivos de Zootecnia [Internet]. 2007 [Acesso Jan 2014]; 56(213):67-70. Disponível em: $<$ http://www.redalyc.org/articulo.oa?id=49556009>. Portuguese.

22. Silva RR, Silva FF da, Carvalho GG de, et al. Avaliação do comportamento ingestivo de novilhas 3/4 Holandês x Zebu alimentadas com silagem de capim- elefante acrescida de $10 \%$ de farelo de mandioca: aspectos metodológicos. Ciência Animal Brasileira [Internet]. 2005 [Acesso Jan 2014]; 6:173-177. Disponível em: $<$ http://www.revistas.ufg.br/index.php/vet/issue/view/36 $>$. Portuguese.

23. Deswysen AG, et al. Nycterohemeral eating and ruminanting patterns in heifers fed grass or corn silage: analysis by finite fourier transform. Journal of Animal Science [Internet]. 1993 [Acesso Jan 2014]; 71(10):2739-2747. Disponível em: $<$ http://www.journalofanimalscience.org/content/71/10/2739. short $>$. English.

24. Silva BANA. Casca de soja e sua utilização na alimentação animal. Revista Eletrônica Nutritime [Internet]. 2004 [Acesso Jan 2014]; 1(1):59-68. Disponível em: $<$ http://www.nutritime.com.br/arquivos_internos/artigos/008V1N1P59_68_JUL2004.pdf $>$._Portuguese.

25. Neto JM, Campos JM de S, Valadares Filho S de C. Comportamento ingestivo de novilhas leiteiras alimentadas com polpa cítrica em substituição ao feno de capim-tifton 85. Revista Brasileira de Zootecnia [Internet]. 2007 [Acesso Jan 2014]; 36(3):618-625. Disponível em: $<$ http://www.scielo.br/pdf/rbz/v36n3/a15v36n3.pdf>. Portuguese.

26. Pazdiora RD, Brondani IL, Silveira MF, Arboitte MZ, Cattelam J, Paula PC. Efeitos da frequência de fornecimento do volumoso e concentrado no comportamento ingestivo de vacas e novilhas em confinamento. Revista Brasileira de Zootecnia [Internet]. 2011 [Acesso Jul 2014]; 40: 2244-2251. Disponível em: $<$ http://www.scielo.br/pdf/rbz/v40n10/v40n10a26.pdf $>$. Portuguese.

27. Polli VA, Restle J, Senna DB, et al. Aspectos relativos à ruminação de bovinos e bubalinos em regime de confinamento. Revista Brasileira de Zootecnia, 25(5):987-993, 1996. Portuguese.

28. Jaster EH, Murphy MR. Effects of varying particle size of forage on digestion and chewing behavior of dairy heifers. Journal of Dairy Science [Internet]. 1983 [Acesso Jan 2014]; 66(6):802-810. Disponível em: $<$ http://www.sciencedirect.com/science/article/pii/S0022030283818608 $>$. English.

29. Marques J de A, Ito RH, Zawadzki F. Comportamento ingestivo de tourinhos confinados com ou sem acesso à sombra. Revista Campo Digital [Internet]. 2007 [Acesso Jan 2014]; 2(1):43-49. Disponível em: $<$ http://people.ufpr.br/ freitasjaf/artigos/boisombra.pdf $>$. Portuguese.

30. Fraser AF, Broom DM. Farm animal behavior and welfare. 3 ed. London: Reprinted. CAB International, 2002. 437p. English. 